АГЕЕВА Анна Викторовна - политолог, аспирант кафедры российской политики факультета политологии Московского государственного университета им. М.В. Ломоносова (119991, Россия, г. Москва, Ломоносовский пр-кт, 27, корп. 4 «Шуваловский»; 92.anпа@таil.ru)

\title{
РОЛЬ ИНСТРУМЕНТОВ «МЯГКОЙ СИЛЫ» ВО ВНЕШНЕЙ ПОЛИТИКЕ РОССИИ
}

Аннотация. В статье рассматриваются роль и значение инструментов «мягкой силы» во внешней политике России. Автор подчеркивает, что роль «мягкой силы» во внешней политике страны усиливается, подтверждением чему является неоднократное использование терминологии и инструментария «мягкой силы» в базовых нормативно-правовых документах, в частности в Концепции внешней политики Российской Федерации. В статье обосновывается вывод, что, наряду с использованием таких инструментов «мягкой силы», как культура, публичная дипломатия, СМИ, образование, наука и др., Россия может оказывать «мягкое» воздействие на акторов мировой политики, используя экономическую силу. Эффективность воздействия «мягкой силы» России на международное сообщество может существенно возрасти также с помощью формирования положительного имиджа РФ внутри страны и за рубежом.

Ключевые слова: «мягкая сила», «твердая сила», экономическая сила, публичная дипломатия, внешняя политика России

$\mathrm{C}$ егодня роль «мягкой силы» (soft power) во внешней политике современных государств продолжает стремительно возрастать. Во многих странах она становится ключевым инструментом внешнеполитического могущества. И Россия - не исключение. Роль технологий «мягкой силы» неуклонно усиливается, поскольку они позволяют «сформировать именно то правительство и общественное мнение, которые будут способствовать реализации национальных интересов как традиционных, так и новых глобальных игроков» [Кошель 2015: 161]. Все крупные геополитические игроки, такие как Россия, Китай, Бразилия, Индия, Турция, а также страны Европейского союза, по возможности расширяют свои инструменты «мягкого» внешнеполитического воздействия на соседние регионы, международные организации и все международное сообщество в целом.

Поднимая вопрос значения термина «мягкая сила», следует отметить, что она действует как сотрудничество и основными ее инструментами являются убеждение и привлечение. Дж. Най уточняет, что «мягкая сила» - больше, чем просто убеждение, уговаривание или способность подвигнуть сделать что-либо при помощи аргументов, хотя все это является важным элементом этой силы. В качестве источников «мягкой силы» страны ученый выделяет культуру, политические ценности, внешнюю политику [Най 2014: 56, 152-153]. Все эти средства и технологии «мягкой силы» выделяются и в современной Концепции внешней политики РФ, где, наряду с военной мощью, выдвигаются такие важные факторы влияния государства на международную политику, «как экономические, правовые, технологические, информационные». А это, в свою очередь, дает возможность использовать экономическую и информационную силу в качестве инструментов «мягкой силы» 1 .

В последние годы в связи с ростом интенсивности темпов глобализации наблюдается рост экономического компонента международных отношений, так называемого экономического измерения дипломатии. Сильная экономика обладает привлекательностью, и в связи с этим она может способствовать увеличению потенциала «мягкой силы» государства. Россия постепенно

\footnotetext{
1 Концепция внешней политики Российской Федерации. Утв. Президентом РФ 12.02.2013. Доступ: http://www.consultant.ru/document/cons_doc_LAW_207990/ (проверено 02.02.2018).
} 
выходит из экономического кризиса: в 2017 г. зафиксирован рост ВВП на 1,5\% после его падения в 2016 г. на 0,2\%. Экономика страны вернулась к ее росту: объем ВВП за 2017 г., по оценке Росстата, составил в текущих ценах 92 81,9 млрд руб. ${ }^{1}$ Прогнозируют, что к 2030 г. он возрастет до 4,74 трлн долл. США, а к 2050 г. - до 7,13 трлн. Это послужит тому, что в топе стран с крупнейшим ВВП по рыночному валютному курсу Россия поднимется с 11-й на 10-ю позицию - показатель возрастет с 1,268 трлн долл. США в 2016 г. до 5,127 трлн в 2050. Как ожидают эксперты, ВВП, в свою очередь, в пересчете на национальную валюту будет увеличиваться на $1,9 \%$ в год ${ }^{2}$. Рост экономики и положительные прогнозы формируют привлекательный имидж России и выступают в качестве основного элемента для потенциальных инвесторов, и в связи с этим - в качестве инструмента «мягкой силы».

Используя свой статус и влияние, а также экономическую силу, Россия может оказывать «мягкое» воздействие на страны - члены Евразийского экономического союза в рамках регулирования деятельности Таможенного союза, в частности по вопросу о деятельности особых экономических зон, предусмотренных Договором о Евразийском экономическом союзе 3 . Особые экономические зоны позволяют государствам решать свои стратегические задачи с точки зрения развития их экономики на перспективу: они являются одним из наиболее масштабных проектов по привлечению прямых инвестиций в приоритетные виды экономической деятельности, например, в рамках развития «обрабатывающих отраслей экономики, высокотехнических отраслей экономики, развития туризма, санаторно-курортной сферы, портовой и транспортной инфраструктуры, разработки технологий и коммерциализации их результатов производства новых видов продукции» ${ }^{4}$. Развитие зон свободной торговли может позволить России увеличить радиус воздействия ее «мягкой силы» на другие страны. Тем не менее на практике данное обстоятельство реализовано еще не в полной мере, соответственно, мы не можем пока говорить об эффективном влиянии зон свободной торговли - это наш возможный «мягкий» ресурс влияния в будущем, на который следует обратить внимание.

Одним из важнейших инструментов экономического влияния на государства является нефть - один из самых важных сырьевых продуктов в мире во всех смыслах - как в экономическом, так и в политическом. На данный момент она является одним из ключевых источников энергии. Дж. Най полагает, что ее влияние не ослабнет на протяжении большей части XXI в. [Най 2014: 121]. Следовательно, нефть продолжает выступать в качестве важного экономического инструмента государства (в т.ч. и России) по оказанию влияния на других акторов на мировом рынке. Например, на начало 2017 г. Россия вышла на 1-е место по добыче нефти, обогнав при этом своего главного конкурента Саудовскую Аравию (члена ОПЕК). По итогам декабря 2016 г. Россия добывала10,49 млн баррелей нефти в сутки, Саудовская Аравия - 10,46 млн баррелей, а США - 8,8 млн, оказавшись на 3-м месте5.

\footnotetext{
1 Росстат сообщил о росте ВВП РФ в 2017 году на 1,5\%. - Интерфакс. 01.02.2018. Доступ: http:// www.interfax.ru/business/598085 (проверено 03.02.2018).

2 России предрекли падение ниже Турции в списке крупнейших экономик мира. - РБК. 26.12.2017. Доступ: https://www.rbc.ru/economics/07/02/2017/5899fc0e9a794785b9230731 (проверено 03.02.2018).

3 Договор о Евразийском экономическом союзе. Подписан в г. Астане 29.05.2014 (ред. от 08.05.2015; с изм. и доп., вступ. в силу с 12.08.2017). Доступ: http://www.consultant.ru/document/cons_doc_LAW_16 3855/5d9b701e2dd72def5faf731400583d66f4be1442 (проверено 02.02.2018).

4 Федеральный закон «Об особых экономических зонах в Российской Федерации» от 22.07.2005 №116-Ф3. Доступ: http://www.consultant.ru/document/cons_doc_LAW_54599/ (проверено 03.02.2018).

5 Россия обогнала Саудовскую Аравию по добыче нефти. - Российская газета. 04.02.2018. Доступ: https://rg.ru/2017/02/20/rossiia-vyshla-v-lidery-po-dobyche-nefti.html (проверено 03.02.2018).
} 
Для России весьма выгодно укрепление связей со странами - производителями сырьевых ресурсов (ОПЕК) с использованием инструментария «мягкой силы». Сегодня влияние России на страны ОПЕК, например посредством организации энергодиалога «Россия-ОПЕК», открывает возможности для применения инструментария «мягкой силы» для снижения темпов и объемов добычи нефти с целью предотвращения снижения ее стоимости на мировом рынке. Подобное влияние можно оказывать как применяя экономическую силу, так и используя публичную дипломатию в качестве инструмента «мягкой силы» [Галумов 2012: 39].

В марте 2018 г. ОПЕК предложила России и другим производителям нефти заключить долгосрочное соглашение по стабилизации рынка нефти ${ }^{1}$. Учитывая, что Россия имеет статус наблюдателя в данной организации, Эр-Рияд достаточно высоко оценивает позиции Москвы, предлагая заключение данного соглашения. Соответственно, можно сказать, что «мягкая сила» России в ОПЕК имеет значительные перспективы для усиления, которые важно использовать в условиях мирового экономического кризиса.

Еще одним важным инструментом «мягкой силы» является публичная дипломатия, направленная на создание благоприятного имиджа страны за рубежом, которая предполагает обращение к общественному мнению других стран через головы правительств ${ }^{2}$. Этот инструмент «мягкой силы» Россия использует, чтобы добиваться объективного восприятия ее в мире, развивать собственные эффективные средства информационного влияния на общественное мнение за рубежом, обеспечивать усиление позиций российских средств массовой информации в мировом информационном пространстве, предоставляя им необходимую государственную поддержку, активно участвовать в международном сотрудничестве в информационной сфере, принимать необходимые меры по отражению информационных угроз ее суверенитету и безопасности ${ }^{3}$. Сегодня в условиях санкций и информационной войны этот источник «мягкой силы» использовать очень сложно. Но среди достаточно успешных примеров недавнего прошлого можно назвать ХІХ Всемирный фестиваль молодежи и студентов 2017 г.

Сегодня идет активная подготовка к Чемпионату мира по футболу 2018 г., хотя информационное противодействие этому мероприятию в мировых каналах СМИ огромное: идет непрерывная компрометация российских спортсменов. Однако активная трансляция позиций России по целому ряду вопросов через СМИ (например, посредством Russia Today) выступает в качестве проводника российской «мягкой силы», способствует разоблачению компромата посредством публичной дипломатии и является инструментом формирования привлекательного образа нашей страны на мировой арене.

Однако в целом на сегодняшний день говорить о высоком уровне влияния российской «мягкой силы» не приходится по целому ряду обстоятельств.

Во-первых, это экономический кризис, который нанес экономике России серьезный урон, что не позволяет позиционировать Россию в качестве государства с высокими темпами экономического развития, страны с развитой экономикой.

Во-вторых, санкции ЕС и США до сих пор оказывают серьезное влияние

1 ОПЕК зовет Россию в десятилетку. - Коммерсант Ђ. 28.03.2018. Доступ: https://www.kommersant. $\mathrm{ru} / \mathrm{doc} / 3586203$ (проверено 28.03.2018).

2 Зонова Т. Публичная дипломатия и ее акторы. - РСМД. 07.08.2012. Доступ: http://russiancouncil.ru/ analytics-and-comments/analytics/publichnaya-diplomatiya-i-ee-aktory/ (проверено 01.02.2018).

3 Концепция внешней политики Российской Федерации. Утв. Президентом РФ 12.02.2013. Доступ: http://www.consultant.ru/document/cons_doc_LAW_207990/ (проверено 02.02.2018). 
на позиции России в мировом сообществе. Солидарность США и ряда европейских стран с позицией Великобритании (несмотря на Brexit) и высылка российских дипломатов говорят о кризисе в отношениях между Россией и странами Запада 1 , что затрудняет использование инструментов публичной дипломатии. Депортация официальных представителей интересов государства, являющихся трансляторами «мягкой силы», с территории зарубежных стран говорит о негласном начале активной информационной войны между государствами. Это обстоятельство наносит серьезный урон имиджу России и говорит о низком уровне «мягкого» воздействия на лидеров иностранных государств.

В-третьих, можно говорить об относительной молодости российской публичной дипломатии, учитывая тот факт, что законодательная база, на которой она основывается, была сформирована только в 2004-2005 гг. [Сорокина 2016: 136]. Соответственно, на сегодняшний день Россия не имеет достаточно высокоразвитого инструментария «мягкой силы». Также политические эксперты утверждают, что объем финансовых средств, выделяемых государственными властями на развитие института публичной дипломатии России, по сравнению с другими странами весьма незначителен [Имидж России... 2014: 20]. Соответственно, качественное развитие данного инструментария «мягкой силы» пока остается под вопросом.

Таким образом, в чрезвычайно сложных современных условиях мировой политики активизировать инструментарий «мягкой силы» России представляется нелегкой задачей. Но решить эту задачу можно и нужно, творчески используя все обозначенные выше каналы влияния.

\section{Список литературы}

Галумов А.Э. 2012. Опыт публичной дипломатии в формировании имиджа Европейского союза в Российской Федерации: дис. ... к.полит.н. М. 167 с.

Имидж России: концепция национального и территориального брендинга (под ред. И.А. Василенко). 2-е изд. 2014. М.: Экономика. 247 с.

Кошель А.С. 2015. Мягкая сила как инструмент гуманитарного сотрудничества государств на евразийском пространстве. - Вестник МГУ. Сер. 18. Социология и политология. № 2. С. 160-172.

Най Дж. (мл.). 2014. Будущее власти (пер. с англ. В.Н. Верченко). М.: АСТ. 444 с.

Сорокина Д.А .2016. Основные этапы развития публичной дипломатии в России. - Власть. № 4. С. 132-137.

\footnotetext{
${ }^{1}$ Высылка дипломатов: ответ России будет нестандартным. - Московский комсомолец. 26.03.2018 г. Доступ: http://www.mk.ru/politics/2018/03/26/vysylka-diplomatov-otvet-rossii-budet-nestandartnym.html (проверено 26.03.2018).
} 
AGEEVA Anna Viktorovna, political scientist, postgraduate student of the Chair of Russian Policy, Faculty of Political Science, Lomonosov Moscow State University, (bld. 4 «Shuvalovskij», 27 Lomonosovsky Ave, Moscow, Russia, 119991; 92.anna@mail.ru)

\title{
THE ROLE OF INSTRUMENTS OF SOFT POWER IN RUSSIA`S FOREIGN POLICY
}

\begin{abstract}
The article discusses the role and importance of the instruments of soft power in Russia's foreign policy. The author emphasizes that today in terms of foreign policy of the state the role of soft power is growing. In many states, it becomes a crucial instrument of foreign policy power. Russia is no exception. One can see it in the repeated use of terminology and tools of soft power reflected in one of the basic legal documents - The Foreign Policy Concept of the Russian Federation. The author supposed, that in addition to using such soft power tools as culture, public diplomacy, media, education, science, etc. Russia also could have a soft influence on the actors of world politics, using economic power. Thereby, through the creation of a positive image of the Russian Federation among Russian nations, which later will be broadcasted through civil society and public organizations, the effectiveness of Russia's soft power impact on the international community can significantly increase.
\end{abstract}

Keywords: soft power, hard power, economic strength, public diplomacy, foreign policy of Russia 